\title{
Spatial pattern and neighbour effects on Helianthemum squamatum seedlings in a Mediterranean gypsum community
}

\author{
Escudero, Adrián ${ }^{1 *}$; Romão, Roberto L. ${ }^{2}$; de la Cruz, Marcelino ${ }^{2} \&$ Maestre, Fernando T. ${ }^{1,3}$ \\ ${ }^{1}$ Unidad de Biodiversidad y Conservación, E.S.C.E.T., Universidad Rey Juan Carlos, Móstoles E-28933, Spain; \\ ${ }^{2}$ Dep. de Biología Vegetal, E.T.S.I., Agrónomos, Universidad Politécnica de Madrid, Madrid, E-28040, Spain; \\ ${ }^{3}$ Department of Biology. Duke University, Phytotron Building, Science Drive, Box 90340, Durham 27708, USA; \\ *Corresponding author: E-mail a.escudero@escet.urjc.es
}

\begin{abstract}
Question: Do, in a semi-arid gypsum environment, neighbours condition the spatial patterns of emergence, survival and height of Helianthemum squamatum seedlings?

Location: Vicinity of Chinchón, province of Madrid, Spain $\left(40^{\circ} 11^{\prime} \mathrm{N}, 3^{\circ} 35^{\prime} \mathrm{W}, 550 \mathrm{~m}\right.$ a.s.1.)

Methods: We evaluated the effects of neighbours on the survival and growth of naturally emerging Helianthemum seedlings in a semi-arid area during a two-year period. We followed a two-fold approach based on the use of neighbour models for seedling survival and growth and spatial point pattern analyses for seedling emergence, taking into account the germination date.

Results: Seedlings appeared clumped in the vicinity of mature Helianthemum individuals. The neighbour models fitted showed that interactions with neighbours were extremely important for the survival and growth of Helianthemum seedlings. These models also suggest that the effects of neighbours on these variables vary with changes in spatial scale and in the abiotic conditions. Some species exerted negative or positive effects on Helianthemum seedlings only at certain spatial scales, and others exerted negative or positive effects at earlier stages of seedling development, but none later and vice versa.

Conclusions: We suggest that the observed patterns are mainly influenced by small-scale modifications in soil conditions and microclimate created by neighbours, which change in time and space.
\end{abstract}

Keywords: Emergence; Neighbour model; Plant-plant interactions; Population dynamics; Seedling growth; Seedling survival; Semi-arid.

Nomenclature: Castroviejo (1986-2004).

Abbreviations: GLM = Generalized linear model.

\section{Introduction}

Plants are sessile after germination, so local conditions around individual plants, including density and size of neighbouring plants, have a critical influence on their growth and survival (Prentice \& Werger 1985; Fowler 1988; Novoplansky \& Goldberg 2001). In arid and semiarid areas, both positive facilitation and negative competition interactions between neighbouring plants are common (Callaway 1995; Fowler 1986). However, much remains unknown about the balance between facilitation and competition in the field, mainly their spatial and temporal variations and the way they shape the whole plant community (Callaway et al. 2002; Maestre et al. 2003a; Pennings et al. 2003; Maestre \& Cortina 2004).

The analysis of the spatial pattern of plant individuals has often been used to infer the outcome of neighbour interactions (Goldberg \& Turner 1986; Callaway 1995; Haase et al. 1996). However, it is often difficult to infer underlying processes from patterns because plant spatial patterns result from processes that can be antagonistic or additive, such as seed dispersal, neighbour interactions and environmental heterogeneity (Barot et al. 1999). Furthermore, and with few exceptions (Goldberg \& Turner 1986; Miriti et al. 1998), most spatial pattern studies are based on analyses performed at a single time point. This makes the evaluation of the role of biotic factors in determining such patterns difficult (Miriti et al. 1998). Nevertheless, spatial pattern analysis is a key tool in generating hypotheses in plant ecology (Dale 1999) and, when clearly identified hypotheses linked to particular patterns are available, it is also a useful predictive tool (Barot et al. 1999).

Some of the limitations of spatial pattern analyses can be offset by incorporating information relative to plant size and age (Haase et al. 1996; Barot et al. 1999; Maestre et al. 2003b). Their predictive power can also be increased by combining such analyses with tools such as individual based neighbourhood models that explicitly account for the positions of individuals (Garret \& Dixon 
1998; Keitt et al. 2002). These models have been employed to quantify intra- and interspecific interactions (Wagner \& Radosevich 1998) and to understand the development of size hierarchies in plant populations (Mitchell-Olds 1987). The combination of spatial pattern analysis and neighbour models seems a powerful approach to explore plant-plant interactions. It overcomes some limitations of spatial pattern analysis by including the possibility of testing specific hypotheses and infer causation taking into account the spatial patterns of the species under study and additional predictors (Keitt et al. 2002).

Here we report results from an observational study in which we evaluated the effects of neighbours on the survival and growth of Helianthemum squamatum seedlings in a semi-arid gypsum environment during a two year period. Seedlings are recognized as the life stage most sensitive to the presence and size of neighbours (Callaway \& Walker 1997; Goldberg et al. 1999). To a large extent, the composition, structure and dynamics of plant communities in semi-arid environments depend on the nature of the environment around seedlings (Fowler 1988; Escudero et al. 1999, 2000).

More specifically, we have the following questions: 1. Are there any intra and interspecific interactions conditioning seedling survival and growth? 2. Do these interactions occur at particular spatial scales? 3. Are there shifts from competition to facilitation and vice versa with changes in time and/or space? and 4. How does germination date influence seedling survival and growth? We followed a two-fold approach based on neighbour models for seedling survival and growth and spatial point pattern analyses for seedling emergence, taking into account the germination date. Such an approach has rarely been used in ecological studies (Keitt et al. 2002), and has not been previously used to model neighbour interactions in arid and semi-arid environments.

\section{Methods}

\section{Study site and species}

The study site was located in the vicinity of Chinchón, in the province of Madrid, Spain $\left(40^{\circ} 11^{\prime} \mathrm{N}, 3^{\circ} 35^{\prime} \mathrm{W}\right.$; 550 $\mathrm{m}$ a.s.1.). The climate is semi-arid, with an annual mean rainfall of $415 \mathrm{~mm}$, but with almost no rainfall in summer. Mean daily maximum and minimum temperatures in January and July are $9.6{ }^{\circ} \mathrm{C}$ and $0.6^{\circ} \mathrm{C}$, and $32.7^{\circ} \mathrm{C}$ and $9.6^{\circ} \mathrm{C}$, respectively. Soils are Calcic gypsisols (Monturiol \& Alcalá del Olmo 1990) and have gypsum contents > $50 \%$. Plant cover, $<25 \%$, is formed by conspicuous vegetated patches interspersed on gypsum crusts with light cover of specialized lichens. Perennial plants are caespitose graminoids (Koeleria castellana) and dwarf creeping chamaephytes such as Helianthemum squamatum, Herniaria fruticosa, Teucrium pumilum and Thymus lacaite. This community belongs to the association Herniario fruticosae-Teucrietum pumilae, which is very poor in species (mean of seven species per relevé; Rivas-Martínez \& Costa 1970).

Helianthemum is an erect dwarf chamaephyte (10-40 $\mathrm{cm})$ that grows at low elevations (40-900 m a.s.l.). It is one of the most representative elements of the gypsum habitats of the Iberian Peninsula. Its fruits are capsules (mean length $3 \mathrm{~mm}$ ) containing small seeds (mean diameter $1.3 \mathrm{~mm}$ ). Seeds have a mucilage coating that favour their adhesion onto soil. Previous studies have shown that the survival of Helianthemum seedlings depends on a complex set of factors including the mechanical strength of the soil surface crust, the distance to the seed sources and the presence of other elements of the community (Escudero et al. 1999).

\section{Field survey}

A rectangular plot measuring $7 \mathrm{~m} \times 6 \mathrm{~m}\left(42 \mathrm{~m}^{2}\right)$ was established on a uniform part of the community in September 1999. The longer side was parallel to the maximum slope $(<5 \%)$. The coordinates $(x, y)$ of the centroid of all the perennial individuals were recorded using a measuring tape. Maximum diameter $\left(d_{1}\right)$ and maximum perpendicular length $\left(d_{2}\right)$ were measured for each plant to estimate the cover with the formula of an ellipsoid: Area $=\left(\pi \cdot d_{1} \cdot d_{2}\right) / 4$. The observational field plot is representative of well conserved remnants of this community in the gypsum outcrops of Central Spain.

Every Helianthemum seedling naturally emerging in the plot was tagged and mapped, and its growth and survival were monitored for 18 months. The first census was carried out in March 2000. One census per month was conducted until mid June, and new surveys were conducted after the summer drought (September 2000), the period of maximum seedling mortality (Escudero et al. 1999), and in June 2001. Emerging seedlings were assigned to one of three cohorts: March, April and Other (remainder of surveys). Maximum height and number of leaves were recorded for any surviving seedling in each census. Mortality causes were grouped into three categories: drought, physical damage and herbivory when clipped (see Escudero et al. 1999). The location of each seedling in relation to vegetated patches was also recorded with a dummy variable $(0,1$; out, within). 


\section{Neighbour models}

In order to build neighbour models, the survival (June 2000, September 2000, June 2001) and height (June and September 2000) of Helianthemum seedlings were used as dependent variables. Cover and density per species of the five most abundant perennial neighbours (see Results) were used as independent variables. As neighbour effects could potentially vary with the radius used to define the neighbourhood (He \& Duncan 2000), we included cover and density information in successively greater surrounding areas, 'rings' of 10, 20 and $30 \mathrm{~cm}$, around individual seedlings. The use of rings ensures that each of the measures for any seedling is basically free to vary independently (Roll et al. 1997). For each ring we estimated cover as the sum of the area covered by every neighbour completely or partially included in the rings, and density as the number of neighbours whose area was completely or partially included in the rings. Rings close to the edge of the plot were corrected for comparisons as follows: cover and density were estimated for the available surface and proportionally weighted to the corresponding area of a complete ring.

To evaluate the relationships between survival and height of Helianthemum seedlings and the independent variables, generalized linear models (GLMs, McCullagh \& Nelder 1989) were built using S-PLUS (Insigthful Corp., Seattle, WA). GLMs were used instead of linear regressions due to their capability of handling a larger class of distributions for the dependent variable. We used a binomial distribution with a logit link function and a Gaussian distribution with an identity link function to model seedling survival and height data, respectively. We conducted a quasi-likelihood approach to overcome possible difficulties in the nature of the data because fewer assumptions are made in estimation and inference (Guisan et al.2002). The independent variables were sequentially included in the models using a stepwise approach based on the magnitude of the Cp statistic at each step (Spector 1994). A smaller Cp corresponds to a better model in the sense of a smaller model residual deviance. The independent variables were included in the model until no additional variables improved it. Model coefficients were tested for significance by $t$-tests. $\chi^{2}$ tests were also conducted to evaluate whether or not selected predictors explain a significant fraction of the deviance (Guisan et al. 2002).

All the independent variables were combined into biologically meaningful groups because progress towards assessing the relative importance of variables can be made by incorporating such subjective knowledge into the analysis (James \& McCulloch 1990; Escudero et al. 2000). The construction of the final models for each independent variable through the evaluation of partial models also minimizes the risks of stepwise procedures
(Guisan \& Zimmermann 2000). The variables previously selected in each of the partial models were used for the evaluation of a 'complete' model, and the significant terms of such a complete model were identified following the described stepwise procedure. Five complementary partial models were developed for each target variable (survival at three dates and growth of Helianthemum seedlings at two dates). Model 1 included the total number of perennial plants and the total number of Helianthemum adults in the three corresponding rings; model 2 included the cover of mature plants and the cover of Helianthemum adults; model 3 included the number of conspecific seedlings; model 4 included the number of individuals of the four most abundant species and model 5 included the cover of each abundant perennial species. As described above, those variables which were selected in each of the partial models were used to build a final complete model for each target variable. In all cases, reduced models (including only the selected variables) were compared with the corresponding saturated model (including all variables previous to the selection procedure); as these models are effectively nested, the change in deviance was tested using an $F$-test. We wanted to know whether the reduced models are good substitutes for the saturated models.

\section{Spatial pattern analyses}

We used Ripley's $K$-functions (Ripley 1977) to quantify the spatial patterns of emerging Helianthemum seedlings and to study the bivariate spatial relationships between these seedlings and the adults of the five most frequent species in the studied community. As is usual in other studies, and for the ease of interpretation and comparison against a random pattern, the $K$-function was transformed into the $L$-function: $L(t)=(K(t) / \pi)^{1 / 2}-t$, as suggested by Ripley (1977). The estimate of the $L$ function at a given distance $t, L(t)$, is expected to be 0 when plants are randomly distributed. A departure from zero indicates that the observed pattern is not random, with positive values of $L(t)$ indicating clustering and negative patterns indicating regularity (Dale 1999). As the sampling distribution of $L(t)$ is unknown, the significance of its departures from zero was tested using Monte Carlo simulations (Besag \& Diggle 1977).

We first tested the null hypothesis that the seedlings were randomly distributed in the plot. Random coordinates of the same number of seedlings were generated 99, and the values of $L(t)$ at the limit of the $2.5 \%$ tails of the randomization were used to build a $95 \%$ confidence interval (Haase 1995). Empirical values that lie outside the confidence limits indicate significant departure from spatial randomness. To test the hypothesis of independence between the spatial pattern of seedling and adult 
individuals of neighbours we used the bivariate estimator $L_{1,2}(t)$ derived from the bivariate $K$-function of Lotwick $\&$ Silverman (1982). This estimator measures the spatial dependence between two spatial patterns. If $L_{1,2}(t)=0$ the patterns are independent; positive and negative values of $L_{1,2}(t)$ indicate positive and negative spatial association of species 1 with species 2 , respectively. Again, $95 \%$ confidence intervals were estimated from the values of the $L_{1,2}(t)$ at the limit of the $2.5 \%$ tails of 99 toroidal shifts of the seedling pattern with respect to the adult pattern (Diggle 1983). Spatial pattern analyses were conducted with the Splancs package (Rowlingson \& Diggle 1993) in the $R$-environment (R Development Core Team; http:// www.R-project.org).

\section{Results}

There were 2221 mature perennial plants in the plot (mean density 52.8 plants $/ \mathrm{m}^{2}$ ), belonging to nine species. The five most abundant species, making up ca. $95 \%$ of the perennial community) are the Iberian endemic gypsophytes Thymus lacaite (793 individuals, 35.7\%); Koeleria castellana $(656,29.5 \%)$; Herniaria fruticosa (258, $11.6 \%)$; Teucrium pumilum (222, 9.9\%); Helianthemum squamatum $(169,7.6 \%)$. The other perennials were rare, and their effect on seedling performance considered negligible. The total cover of the perennial plants was $17 \%$.

The number of tagged seedlings was 871 ; only 788 were suitable for inclusion in the neighbour models because information was lost for the others. Most seedlings belonged to the March (62\%) and April cohorts (21.4\%), although germination did extend to June (2.6\%). Survival in June 2000 reached $83.8 \%$, falling to $47.7 \%$ and $38.7 \%$ in September 2000 and June 2001, respectively. Most seedlings emerged within a vegetated patch $(61.9 \%)$, and summer drought was the primary cause of death $(>90 \%)$.

Complete models for survival (in June and September 2000 and June 2001) and height (in June and September 2000) were efficient substitutes for the corresponding saturated models $(P>0.05)$. The results of the 15 partial models fitted to seedling survival data are shown in App. 1 ; only three were not significant. Complete model for survival in June 2000 - using those variables previously selected in the partial models - included five variables (Table 1), being the number of Herniaria individuals in the $20 \mathrm{~cm}$ ring and total number of neighbours in the 30 $\mathrm{cm}$ ring the most important independent variables for explaining survival patterns. That of survival in September 2000 included four variables; the number of Koeleria individuals in the $30 \mathrm{~cm}$ ring and the number of neighbour seedlings in the $10 \mathrm{~cm}$ ring were the two most relevant for explaining observed survival patterns. The complete model for survival in June 2001 included five variables. The cover of Herniaria and the number of conspecific seedlings in a $10 \mathrm{~cm}$ ring had negative coefficients, while the cover of Helianthemum in a $20 \mathrm{~cm}$ ring and the cover of Koeleria in a $30 \mathrm{~cm}$ ring had positive coefficients. In addition, we added the time of emergence and the situation of each seedling in relation to vegetated patches in the complete models for the three survival periods. Only the emergence time was selected $(P<0.001)$. This pre-

\begin{tabular}{|c|c|c|c|c|c|c|c|}
\hline \multirow{2}{*}{$\begin{array}{l}\text { Variable } \\
\text { Survival in June } 2000\end{array}$} & \multirow[t]{2}{*}{ df } & \multicolumn{2}{|c|}{$\begin{array}{r}\text { Coefficient } \\
\text { (SE) }\end{array}$} & & \multirow[t]{2}{*}{$t \quad(P)$} & \multicolumn{2}{|c|}{$\begin{array}{r}\chi^{2} \text { test on deviance } \\
(P)\end{array}$} \\
\hline & & & & & & & \\
\hline Null & 787 & & & & & 695.96 & \\
\hline Intercept & & 0.82 & $(0.316)$ & 2.58 & $(0.023)$ & & \\
\hline H.f. neighbours $20 \mathrm{~cm}$ & 1 & -0.34 & $(0.088)$ & -3.85 & $(0.002)$ & 688.23 & $(0.005)$ \\
\hline Total neighbours $30 \mathrm{~cm}$ & 1 & 0.06 & $(0.017)$ & 3.26 & $(0.006)$ & 674.73 & $(0.002)$ \\
\hline T.p. neighbours $20 \mathrm{~cm}$ & 1 & 0.11 & $(0.069)$ & 1.57 & $(0.140)$ & 669.59 & $(0.023)$ \\
\hline K.c. cover $20 \mathrm{~cm}$ & 1 & -0.01 & $(0.002)$ & -2.35 & $(0.036)$ & 665.95 & $(0.056)$ \\
\hline H.s. seedlings $30 \mathrm{~cm}$ & 1 & -0.05 & $(0.022)$ & -2.16 & $(0.051)$ & 661.21 & $(0.029)$ \\
\hline \multicolumn{8}{|c|}{ Survival in September 2000} \\
\hline Null & 787 & & & & & 1090.93 & \\
\hline Intercept & & -0.46 & $(0.165)$ & -2.78 & $(0.016)$ & & \\
\hline K.c. neighbours $30 \mathrm{~cm}$ & 1 & 0.08 & $(0.020)$ & 3.80 & $(0.002)$ & 1079.79 & $(0.000)$ \\
\hline H.s. seedlings $10 \mathrm{~cm}$ & 1 & -0.06 & $(0.020)$ & -3.13 & $(0.008)$ & 1069.80 & $(0.001)$ \\
\hline T.p. cover $30 \mathrm{~cm}$ & 1 & 0.0008 & $(<0.001)$ & 2.05 & $(0.062)$ & 1063.59 & $(0.012)$ \\
\hline H.s. cover $20 \mathrm{~cm}$ & 1 & 0.003 & $(0.002)$ & 1.76 & $(0.100)$ & 1060.39 & $(0.074)$ \\
\hline \multicolumn{8}{|l|}{ Survival in June 2001} \\
\hline Null & 786 & & & & & 1050.86 & \\
\hline Intercept & & -0.07 & $(0.161)$ & -4.31 & $(0.001)$ & & \\
\hline K.c. neighbours $30 \mathrm{~cm}$ & 1 & 0.08 & $(0.020)$ & 3.72 & $(0.002)$ & 1040.33 & $(0.001)$ \\
\hline H.f. cover $20 \mathrm{~cm}$ & 1 & -0.01 & $(0.002)$ & -2.58 & $(0.024)$ & 1030.96 & $(0.002)$ \\
\hline H.s. cover $20 \mathrm{~cm}$ & 1 & 0.003 & $(0.001)$ & 2.35 & $(0.036)$ & 1026.35 & $(0.032)$ \\
\hline H.s. seedlings $10 \mathrm{~cm}$ & 1 & -0.05 & $(0.022)$ & -2.25 & $(0.043)$ & 1021.05 & $(0.021)$ \\
\hline H.s. cover $20 \mathrm{~cm}$ & 1 & 0.003 & $(0.002)$ & 1.76 & $(0.100)$ & 1060.39 & $(0.074)$ \\
\hline
\end{tabular}

Table 1.Parameters and $t$-values for the GLMs fitted to Helianthemum squamatum seedling survival data. Goodness of fit is evaluated by means of the change in deviance and the corresponding $\chi^{2}$ test and fit for the so-called complete models of seedling survival after stepwise selection. H.f. = Herniaria fruticosa; T.p. = Teucrium pumilum; K.c.= Koeleria castellana; H.s. = Helianthemum squamatum. 
dictor presented negative coefficients in the three cases. The adjusted $D^{2}$ values for the complete models - following Guisan \& Zimmermann (2000) - were relatively small in the three cases (5\%-10\%).

Results for the partial models fitted to seedling height data are shown in App. 2; only one of the models (Model 3 for September 2000) was not significant. The complete model for height in June and September included eight and three predictors, respectively (Table 2). In both cases, the time of emergence and the patch location were the most relevant predictors.

The spatial pattern analyses of all Helianthemum seedlings emergences (Fig. 1) showed a non-random pattern for a wide range of radii $(0-250 \mathrm{~cm})$, reaching a peak between 40 and $140 \mathrm{~cm}$. This pattern was also maintained in the three considered cohorts (March, April and Other). Bivariate relationships with mature individuals of Helianthemum showed a similar pattern, with a positive association between both elements detected at distances below $150 \mathrm{~cm}$ (Fig. 2). A similar pattern was found in the spatial relationships between Helianthemum seedlings and mature plants of Koeleria, but at a shorter distance $(<50 \mathrm{~cm})$. Positive association with Thymus was found at all distances, but on the edge of statistical significance. The spatial pattern of Helianthemum seedlings was not related to those of Teucrium and Herniaria.

\section{Discussion}

Our two-fold approach relieves the limitations of most spatially explicit approaches, as it allows the incorporation of relevant knowledge and evaluation of intraand interspecific interactions. However, it does not provide evidence of the mechanisms underlying the relationships and patterns found, which require the establishment

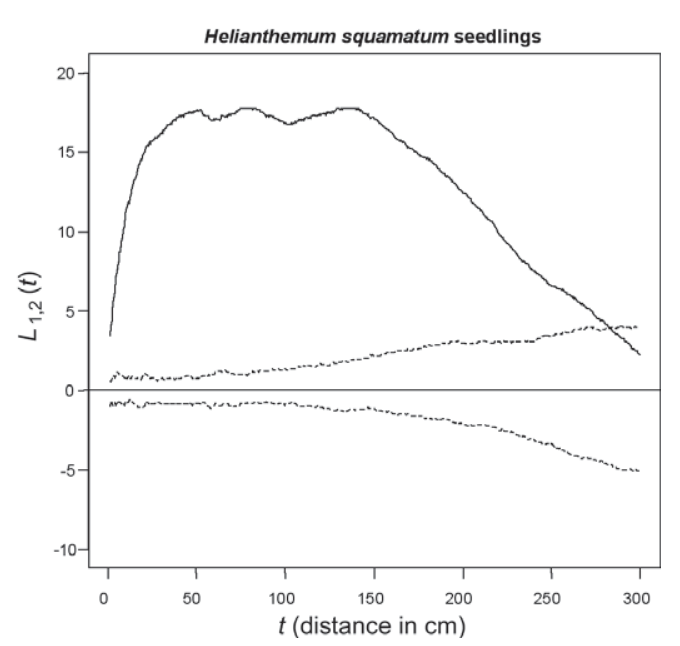

Fig. 1. Spatial pattern of emerging Helianthemum squamatum seedlings evaluated with the function $L(t)$. All seedlings were included in the analysis. Solid line: observed $L(t)$; dashed lines: $95 \%$ confidence envelopes obtained from 99 simulations of random coordinates. Solid horizontal line at 0 provides a reference for complete spatial randomness of the pattern. The three considered cohorts were merged because they showed very similar patterns.

of further experiments. Spatial pattern analyses revealed that Helianthemum seedlings mainly emerged near mature conspecific individuals. This is related to short dispersal and seed characteristics, e.g. the presence of a hard waxy layer that turns gelatinous when wetted (Escudero et al. 1997, 1999). These two features seem to be adaptive on crusted surfaces of gypsum outcrops. According to the 'Mother Site Advantage' hypothesis (Ellner \& Shmida 1981), long-range dispersal may be inefficient when the most favourable environment is located near the mother plant and the distribution of similar environments is
Table 2. Parameters and $t$-values for the GLM models fitted to Helianthemum squamatum seedling height data. Goodness of fit is evaluated by means of the change in deviance and the corresponding $\chi^{2}$ test and fit for the so-called complete models of seedling height after stepwise selection. H.f. = Herniaria fruticosa; T.p.=Teucrium pumilum; K.c. = Koeleria castellana $;$ H.s. = Helianthemum squamatum. The time of emergence and location of each seedling in relation to vegetated patches were also included in the complete models.

\begin{tabular}{|c|c|c|c|c|c|c|c|}
\hline \multirow{2}{*}{$\begin{array}{l}\text { Variable } \\
\text { Height in June } 2000\end{array}$} & \multirow[t]{2}{*}{$\mathrm{df}$} & \multicolumn{2}{|c|}{$\begin{array}{r}\text { Coefficient } \\
\text { (SE) }\end{array}$} & & \multirow[t]{2}{*}{$(P)$} & \multicolumn{2}{|c|}{$\begin{array}{r}\chi^{2} \text { test on deviance } \\
(P)\end{array}$} \\
\hline & & & & & & & \\
\hline Null & 655 & & & 520.41 & & & \\
\hline Intercept & & 2.14 & $(0.104)$ & 20.51 & $(<0.001)$ & & \\
\hline Time of emergence & 1 & -0.38 & $(0.040)$ & -9.24 & $(<0.001)$ & 445.37 & $(<0.001)$ \\
\hline Total cover $10 \mathrm{~cm}$ & 1 & 0.001 & $(<0.001)$ & 7.10 & $(<0.001)$ & 415.69 & $(<0.001)$ \\
\hline H.f. neighbours $30 \mathrm{~cm}$ & 1 & -0.03 & $(0.019)$ & -3.79 & $(0.002)$ & 400.53 & $(<0.001)$ \\
\hline Patch location & 1 & 0.29 & $(0.064)$ & 4.54 & $(<0.001)$ & 389.41 & $(<0.001)$ \\
\hline T.p. neighbours $10 \mathrm{~cm}$ & 1 & -0.21 & $(0.050)$ & -4.05 & $(0.001)$ & 383.53 & $(0.015)$ \\
\hline T.1. cover $10 \mathrm{~cm}$ & 1 & 0.001 & $(<0.001)$ & -4.06 & $(0.001)$ & 373.24 & $(0.001)$ \\
\hline H.f. cover $10 \mathrm{~cm}$ & 1 & -0.004 & $(0.0014)$ & -2.77 & $(0.016)$ & 369.18 & $(0.044)$ \\
\hline H.s. neighbours $20 \mathrm{~cm}$ & 1 & 0.073 & $(0.025)$ & 2.86 & $(0.014)$ & 365.16 & $(0.044)$ \\
\hline \multicolumn{8}{|c|}{ Height in September 2000} \\
\hline Null & 371 & & & 606.38 & & & \\
\hline Intercept & & 2.85 & $(0.208)$ & 13.66 & $(<0.001)$ & & \\
\hline Patch location & 1 & 0.30 & $(0.138)$ & 2.20 & $(0.047)$ & 594.29 & $(<0.001)$ \\
\hline H.f. neighbours $30 \mathrm{~cm}$ & 1 & -0.09 & $(0.038)$ & -2.33 & $(0.037)$ & 581.44 & $(<0.001)$ \\
\hline Moment of emergence & 1 & -0.23 & $(0.101)$ & -2.24 & $(0.044)$ & 574.17 & $(0.007)$ \\
\hline
\end{tabular}



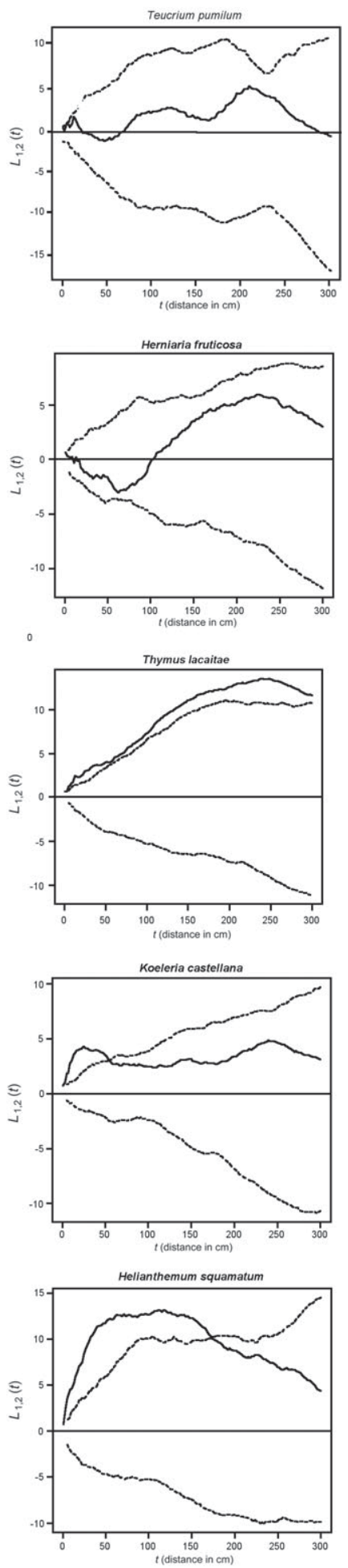

Fig. 2. Bivariate $L_{1,2}(t)$ functions between Helianthemum squamatum seedlings and adult individuals of the five most abundant species in the community. Solid line: observed $L_{1,2}(t)$; dashed lines: $95 \%$ confidence limits obtained from 99 random toroidal shifts. Solid horizontal line at 0 provides a reference for independence of the two spatial patterns. Seedling cohorts were merged in a unique type. unpredictable (Escudero et al. 1999, 2000).

We recently found that Helianthemum maintains a high local seed bank in gypsum environments of central Spain (322 seeds $\mathrm{m}^{-2}$ in the transient bank; Caballero et al. 2003). This seed bank appears spatially structured with higher values in the proximity of mature plants, both in the case of the transient bank (immediately after dispersal) but also in the case of the persistent bank (Caballero et al. in press). In common with many desert perennial plants (Milton 1995), persistent seed banks have a relatively minor importance in the establishment of Helianthemum (Escudero et al. 1999). The bivariate spatial patterns of Helianthemum seedlings with the most abundant perennials were not significantly different from random. An aggregated pattern was only apparent with Koeleria, but only at very short distances. This association could be linked to the growth habit of this grass, which forms dwarf tussocks that are able to trap seeds transported by wind and run-off.

Despite the long history of studying spatial patterns in plant communities and describing spatial pairwise interactions between major community elements (Dale 1999), few studies so far have jointly studied such patterns with those of emergence, survival and growth (Miriti et al. 1998; Maestre et al. 2003b). Our results suggest that the factors controlling the survival and growth of Helianthemum seedlings are extremely complex, and that the effects of neighbours vary with changes in spatial and time scales and in the abiotic conditions. Some species exerted negative or positive effects on these seedlings only at certain scales, and others exerted negative or positive effects at earlier stages of seedling development, but none later and vice versa.

Field studies of plant-plant interactions have highlighted the relevance of multiple stress gradients and the structure of dominant species at the scale at which facilitative effects are apparent (Greenlee \& Callaway 1996; Maestre \& Cortina 2004; Maestre et al. in press). Furthermore, they have detected that the magnitude of the net effect of a given plant-plant interaction can change over time (Holzapfel \& Mahall 1999; Tielbörger \& Kadmon 2000). Our findings suggest that such shifts in interactions at different, but small, spatial and temporal scales, are not exceptions, but a rule, in the studied community. At small spatial scales, plant-plant interactions largely depend on how plant species modify their environment, which usually includes changes in microclimate, nutrient dynamics and soil water content (Callaway 1995; Maestre et al. 2003a; Pugnaire et al. 2004). Survival and growth of Helianthemum seedlings were largely dependent on the proximity of mature individuals of the dominant community species, as found in other similar ecosystems (Miriti et al. 1998; Tewskbury \& Lloyd 2001). Although changes in water availability 
have been suggested as the most important factor mediating facilitation and competition in semi-arid environments (Casper \& Jackson 1997; Maestre et al. in press), recent evidence suggests that soil nutrients (Puignaire et al. 2004) and even some soil surface physical properties (Maestre et al. 2003a) may also play a major role in these interactions, especially in gypsum environments (Escudero et al. 1999). However, the mechanisms underlying neighbour interactions found cannot be readily addressed by our study, and their elucidation merits further manipulative experiments.

The number of conspecific seedlings had also a significant negative effect on the survival of Helianthemum seedlings, suggesting the presence of intraspecific competition. It has been suggested that small seedlings are much more sensitive to the presence of neighbours than adult plants (Goldberg et al. 1999; Foster 1999). Helianthemum seeds germinate with a spatially clumped distribution, but there is a negative interaction among emerging seedlings for survival. It should be noted that cover and number of conspecific mature plants exerted a positive effect on survival. Such a positive effect may be a direct consequence of the amelioration of microclimate and the improvement of soil conditions under the canopy of the mature individuals. In contrast to our initial expectations, emergence within a patch was not selected in the survival models, but was selected in growth models with positive coefficients. However, plants within patches are significantly larger, and seedling size was found to be a good predictor of survival in a previous study covering a wide array of gypsum communities (Escudero et al. 2000). Nevertheless, early asymmetries could be exaggerated in the adult plants (Bergelson \& Perry 1989), which, although not selected in the seedling stage, could become crucial in late stages of plant development. As rainfall during the course of the study was above the normal mean (data not shown), results should be interpreted with caution because interactions at very small distances could differ under more stressful conditions.

Finally, germination date was included in all the GLMs, and always with a positive coefficient. Seedlings from early cohorts usually have a better chance of surviving and of achieving a higher mean size, a pattern that has been found in other gypsum environments (Escudero et al. 1999). In our case this may be related to the ability of the seedlings that germinate earlier to make use of spring rainfall, which occurs mainly during March-April at the study site.

In conclusion, emergence, survival and growth at the early stages of Helianthemum development depend on small-scale and complex biotic interactions with neighbours that shift in time and space. Thus, a complex network of interactions varying at spatial and temporal scales seems to be the key force of coexistence and structure in the studied semi-arid gypsum community.

Acknowledgements. We thank Luis Giménez and Dr. Albert ('Pizca') for collaboration during field work. We also thank Jan Lepš and three anonymous referees for their valuable comments. Financial support was provided by a MCYT project to AE (REN2003-03366). The work of FTM was supported by a MEC/Fulbright fellowship.

\section{References}

Barot, S., Gignoux, J. \& Menaut, J.C. 1999. Demography of a savanna palm tree: Predictions from comprehensive spatial pattern analyses. Ecology 80: 1987-2005.

Bergelson, J. \& Perry, R. 1989. Interspecific competition between seeds - Relative planting date and density affect seedling emergence. Ecology 70: 1639-1644.

Besag, J. \& Diggle, P.J. 1977. Simple Monte Carlo tests for spatial pattern. Appl. Stat. 26: 327-333.

Caballero, I., Olano, J.M., Loidi, J. \& Escudero, A. 2003. Seed bank structure along a semiarid gypsum gradient in Central Spain. J. Arid Env. 55: 287- 299.

Caballero, I., Olano, J.M., Luzuriaga, A.L. \& Escudero, A. In press. Spatial coherence between seasonal seed banks in a semiarid gypsum community: density changes but structure does not. Seed Sci. Res.

Callaway, R.M. 1995. Positive interactions among plants. Bot. Rev. 61: 306-349.

Callaway, R.M. \& Walker,L.R. 1997. Competition and facilitation: a synthetic approach to interactions in plant communities. Ecology 78: 1958-1965.

Callaway, R.M., Brooker, R.W., Choler,P., Kikvidze,Z., Lortie, C.J., Michalet, R., Paolini, L., Pugnaire, F.I., Newingham, B., Aschehoug, E.T., Armas, C., Kikodze, D. \& Cook, B.J. 2002. Positive interactions among alpine plants increase with stress. Nature 417: 844-888.

Casper, B.B. \& Jackson, R.B. 1997. Plant competition underground. Annu. Rev. Ecol. Syst. 28: 545-570.

Castroviejo, S. (ed.) 1986-2004. Flora Iberica. CSIC. Madrid, ES.

Dale, M.R.T. 1999. Spatial pattern analysis in plant ecology. Cambridge University Press, Cambridge, UK.

Diggle, P.J. 1983. Statistical analysis of spatial point patterns. Academic Press, New York, NY, US.

Ellner, S. \& Shmida, A. 1981. Why are adaptations for long range seed dispersal rare in desert plants. Oecologia 51: 133-144.

Escudero, A., Carnes, L. \& Pérez-García, F. 1997. Germination of gypsophytes and gypsovags in semiarid central Spain. $J$. Arid Environ. 36: 487-497.

Escudero, A., Somolinos, R.C., Olano, J.M. \& Rubio, A. 1999. Factors controlling the establishment of Helianthemum squamatum (L.) Dum., an endemic gypsophile of semi-arid Spain. J. Ecol. 87: 290-302. 
Escudero, A., Iriondo, J.M., Olano, J.M., Rubio, A. \& Somolinos, R. 2000. Factors affecting establishment of a gypsophite: the case of Lepidium subulatum. Am. J. Bot. 87: 861- 871.

Foster, B.L. 1999. Establishment, competition, and the distribution of native grasses among Michigan old fields. J. Ecol. 87: 476-489.

Fowler, N. 1986. The role of competition in plant communities in arid and semiarid regions. Ann. Rev. Ecol. Syst. 17: 89110 .

Fowler, N. 1988. What is a safe site? Neighbor, litter, germination date, and patch effects. Ecology 69: 947-961.

Garret, K.A.\& Dixon,P.M. 1998. When does the spatial pattern of weeds matter? Predictions from neighborhood models. Ecol. Appl. 8: 1250-1259.

Goldberg, D.E. \& Turner, R.M. 1986. Vegetation changes and plant demography in permanent plots in the Sonoran Desert. Ecology 67: 695-712.

Goldberg, D.E., Rajaniemi, T., Gurevitch, J. \& Stewart-Oaten, A. 1999. Empirical approaches to quantifying interactions intensity: Competition and facilitation along productivity gradients. Ecology 80: 1118-1131.

Greenlee, J. \& Callaway, R. 1996. Effects of abiotic stress on the relative importance of interference and facilitation. Am. Nat. 148: 386-396.

Guisan, A. \& Zimmermann, N.E. 2000. Predictive habitat distribution models in ecology. Ecol. Model. 135: 147-186.

Guisan, A., Edwards Jr., T.C. \& Hastie, T. 2002. Generalized linear and generalized additive models in studies of species distributions: setting the scene. Ecol. Model. 157: 89-110.

Haase, P. 1995. Spatial pattern analysis in ecology based on Ripley's $K$-function: Introduction and methods of edge correction. J. Veg. Sci. 6: 575-582.

Haase, P., Puignaire, F.I., Clark, S.C. \& Incoll, L.D. 1996. Spatial patterns in a two-tiered semi-arid shrubland on abandoned land in southeastern Spain. J. Veg. Sci. 7: 527534.

He, F. \& Duncan, R.P. 2000. Density-dependent effects on tree survival in an old-growth Douglas fir-forest. J. Ecol. 88: 676-688.

Holzapfel, C. \& Mahall, B.E. 1999. Bidirectional facilitation and interference between shrubs and annuals in the Mojave Desert. Ecology 80: 1747-1761.

James, F.C. \& McCulloch, C.E. 1990. Multivariate analysis in ecology and systematics: Panacea or Pandora's box. Annu. Rev. Ecol. Syst. 21: 129-166.

Keitt, T.H., Bjornstad, O.N., Dixon, P.M. \& Citron-Pousty, S. 2002. Accounting for spatial pattern when modeling organism-environment interactions. Ecography 25: 616-625.

Lotwick, H.W. \& Silverman, B.W. 1982. Methods for analysing spatial processes of several types of points. J. R. Stat. Soc. B 44: 406-413.

Maestre, F.T., Bautista, S. \& Cortina, J. 2003a. Positive, negative, and net effects in grass-shrub interactions in Mediterranean semiarid grasslands. Ecology 84: 3186-3197.

Maestre, F.T. \& Cortina, J. 2004. Do positive interactions increase with abiotic stress? A test from a semi-arid steppe. Proc. R. Soc. Lond. B (Suppl.) 271: S331-S333.

Maestre, F.T., Cortina, J., Bautista, S., Bellot, J. \& Vallejo, R. 2003b. Small-scale environmental heterogeneity and spatio- temporal dynamics of seedling establishment in a semiarid degraded ecosystem. Ecosystems 6: 630-643.

Maestre, F.T., Valladares, F. \& Reynolds, J.F. 2005. Is the change of plant-plant interactions with abiotic stress predictable? A meta-analysis of field results in arid environments. J. Ecol. 93: 748-757.

McCullagh,P.\& Nelder, J.A. 1989. Generalized linear models. Chapman and Hall, New York, NY, US.

Milton, S.J. 1995. Spatial and temporal patterns in the emergence and survival of seedlings in arid Karoo shrubland. $J$. Appl. Ecol. 32: 145-156.

Miriti, M.N., Howe, H.F. \& Wright, S.J. 1998. Spatial patterns of mortality in a Colorado Desert plant community. Plant Ecol. 136: 41-51.

Mitchell-Olds, T. 1987. Analysis of local variation in plant size. Ecology 68: 82-87.

Monturiol,F.\& Alcalá del Olmo,L. 1990. Mapa de asociaciones de suelo de la comunidad de Madrid. Escala 1:200.000. Comunidad de Madrid, Madrid, ES.

Novoplansky, A. \& Goldberg, D.E. 2001. Effects of water pulsing on individual performance and competitive hierarchies in plants. J. Veg. Sci. 12: 199-208.

Pennings, S.C., Seling, E.R., Houser, L.T. \& Bertness, M.D. 2003. Geographic variation in positive and negative interactions among salt marsh plants. Ecology 84: 1527-1538.

Prentice, I.C. \& Werger, M.J.A. 1985. Clump spacing in a desert dwarf shrub community. Vegetatio 63: 133-139.

Puignaire, F.I., Armas, C.\& Valladares, F. 2004. Soil as mediator in plant-plant interactions in a semi-arid community. $J$. Veg. Sci. 15: 85-92.

Ripley, B.D. 1977. Modelling spatial patterns. J.R. Stat. Soc. B 39: 172-212.

Rivas-Martínez, S. \& Costa, M. 1970. Comunidades gipsícolas del centro de España. Anal. Inst. Bot. Cav. 27: 195-223.

Roll, J., Mitchell, R.J., Cabin, R.J. \& Marshall, D.L. 1997. Reproductive success increases with local density of conspecifics in a desert mustard (Lesquerella fendleri). Conserv. Biol. 11: 738-746.

Rowlingson, B.\& Diggle, P. 1993 Splancs: spatial point pattern analysis code in S-Plus. Comp. Geosci. 19: 627-655.

Spector, P. 1994. An introduction to $S$ and S-Plus. Duxbury Press, Belmont, CA, US.

Tewksbury, J.T.\& Lloyd, J.D. 2001. Positive interactions under nurse-plants: spatial scale, stress gradients and benefactor size. Oecologia 127: 425-434.

Tielbörger, K. \& Kadmon, R. 2000. Temporal environmental variation tips the balance between facilitation and interference in desert plants. Ecology 81: 1544-1533.

Wagner, R.G. \& Radosevich, S. 1998. Neighborhood approach for quantifying interspecific competition in coastal Oregon Forests. Ecol. Appl. 8: 779-794.

Received 10 November 2004;

Final version accepted 9 June 2005 Co-ordinating Editor: J. Lepš. 
Copyright of Journal of Vegetation Science is the property of Opulus Press. The copyright in an individual article may be maintained by the author in certain cases. Content may not be copied or emailed to multiple sites or posted to a listserv without the copyright holder's express written permission. However, users may print, download, or email articles for individual use. 